\title{
Friends, Neighbors, and Boundaries
}

\author{
Susan Oyama \\ John Jay College of Criminal Justice and The Graduate Center \\ The City University of New York (Professor Emerita)
}

I'll forgo the usual primer on Developmental Systems Theory (DST) for this little intervention: as a perspective, however, it will be holographically present, and some of its features will be made explicit along the way. Instead, I'll just sketch some problems I've been thinking about, all of which circle around the theme of boundaries in organism-environment systems. For reasons that will become evident, in addressing the developmental systems framework I speak only for myself.

The friends and neighbors of my title are obviously theoretical ones. They are so not so much different groups - the categories certainly overlap-as they are different aspects of our collegial relationships. Friends should be understood as enemies of my enemy, those with whom we make common cause. They are by our side at some scholarly barricade or other, perhaps engaging in the critiques of biological or social determinism that were part of my own academic development, or more recently of a variety of genecentrisms, adaptationism, representationalism, or the dominant strains of evolutionary psychology. ${ }^{1}$ Such friends and allies tend to encounter each other on panels, in edited volumes, at workshops; on the page they often line up in the same citation-laden parentheses.

The question of neighbors arises afterward, on the way home from the barricades, perhaps, when a united front is no longer necessary and you gaze at

*This is the fifth paper in the series, "On the Notion and Implications of Organism-Environment System," based on presentations given at the University of Connecticut, May 15-16, 2008.

Correspondence should be addressed to Susan Oyama. E-mail: soyama48@ verizon.net

${ }^{1}$ That is, what Poirier, Faucher, and Lachapelle (2005) dub GOFEP, or Good Old-Fashioned Evolutionary Psychology, to signal its reliance on the cognitivism of Good Old-Fashioned Artificial Intelligence, or GOFAI. To this menagerie I'm inclined to add GOFIB: Good Old-Fashioned Infocentric Biology. 
each other on the bus. Now the questions become: Who are you, and what are you doing next to me? Or more specifically, On what do we really agree? What are our sticking points, and are they resolvable or terminal? How important is it to work through our various disagreements? Do early commitments preclude our being any more than theoretical neighbors, harboring similar complaints and irritations but kept apart by differences of academic culture and other impediments to mutual integration?

The boundaries of my title thus refer not only to the limits of entities like cells and organisms but to the borders of our own conceptual (and social) systems. I bring you three kinds of boundary issues that arise with sometimes quite near and dear friends and neighbors: (a) causal relations across system boundaries, (b) "information flows" across those perimeters, and (c) borders around developmental systems.

\section{BOUNDARY ISSUES}

\section{Causal Relations Across System Boundaries}

Causal relations first. During a certain period, my work was often lumped with that of people like Stuart Kauffman $(1983,1985,1993)$ on complex systems; Brian Goodwin (1970, 1982, 1984, 1994) and his laws of form, constraints on evolution, and sometimes ambivalent attitude toward history; or Humberto Maturana and Francisco Varela (1987; Varela, 1979), with their self-creating autopoietic entities: "friends" with comparable objections to models of central control in biology and to a certain kind of overheated neo-Darwinism. Whenever we encountered each other, however, our mild but recurrent disagreements made me wonder how close we actually were as theoretical neighbors, even though we shared a preoccupation with circular causation, dense interdependencies, and the coemergence of living entities and their surrounds.

My own work on development began with the nature-nurture problem, in the context of the emphatic nativism of Chomskian formal linguistics and the rise of sociobiology. As I worked through a variety of related oppositions, such as innate vs. acquired, gene vs. environment, biological vs. cultural, body vs. mind, I found externalisms, which privileged outsides, and internalisms, which gave primary causal power to insides, to be problematic in similar ways. Because traditional organism-environment boundaries stood in the way of the conceptual changes required for a more satisfactory (to me) way of dealing with development and evolution, both kinds of causal asymmetries were vexing: they supported just the invidious distinctions I was convinced needed to be dissolved.

My hunch is that history is as important for understanding these theoretical preferences as it is for certain pathways in dynamical systems: early contingencies may hinder later convergence with other paths. Unlike theorists of 
autopoiesis, for example, or students of physical laws and complexity in biology, I was never focused on characterizing life and its origins, on defining identity or biological units, distinguishing life from nonlife, or articulating general laws of form. Perhaps this helps explain why I don't share those theorists' penchant for delineating interior spaces by asymmetrical causal relations. Think of Robert Rosen's placement of efficient causes inside the systems he studied, leaving outsides to supply raw materials. ${ }^{2}$ Similarly, Maturana and Varela (1987) distinguished between the internal specifying power of an autopoietic system and external triggering (see also Goodwin, 1994, p. 164). In DST, causal interactions across a boundary are symmetrical. Insides and outsides define and "specify" each other as developmental interactants, codetermining outcomes (Oyama, 2000a, 2000b), so that responsibility for the result itself cannot be partitioned. No causally sufficient self-making here (at least not in the internalist style of some theorists); instead, we have mutually constructing relations of organisms and their developmental environments. Specific comparisons may highlight factors inside an organism or outside it: variation in one interactant may be correlated with variation in outcome, say. This allows us to ask those nature-nurture questions that are empirically intelligible (for instance, whether and under what circumstances a genetic or environmental difference makes a developmental difference in some feature) without locking in an incoherent set of background assumptions (that some features are formed from internal genetic representations, while others are shaped by the environment, or that some aspects of organisms must develop and others need not because they are already prefigured in the genome). Instead, the background ontology consists of a network of interdependent, heterogeneous contributors to development. Notice that italicized phrase: under what circumstances. To my mind, one of the virtues of DST is that it explicitly and insistently keeps this kind of contextsensitivity in the foreground. It acknowledges and theorizes such relations rather than reluctantly, lamely, dragging them in when research fails to produce results as simple and sweeping as the framework that generated it. ${ }^{3}$

\section{"Information Flows" Across Boundaries}

Another candidate for boundary work is the notion of transgenerational information "flow," often described as occurring through "channels." Here I am thinking

\footnotetext{
${ }^{2}$ For some reason Rosen seems to have been on a different circuit (at least I never met him), but judging from Bechtel (2007), Chemero and Turvey (2008), and Thompson (2007), on whose discussions I draw, he could have been included in the pool of circulating panel members mentioned earlier.

${ }^{3}$ It should not escape the notice of those perpetually fretting about their next grant that my modest parenthesis points toward worlds of research proposals.
} 
of some recent sophisticated attempts to stretch the notion of heredity beyond genes, or even beyond gene-culture coevolution. ${ }^{4}$

These efforts to increase the number of paths for cross-generational movement of information include the niche-construction work of Laland, Odling-Smee, and Feldman (2001) and the multiple inheritance schemes of Eva Jablonka (2001) and her coworkers (Avital \& Jablonka, 2000; Jablonka \& Lamb, 1995, 2005). These are certainly close neighbors to DST, sharing as they do the pages of the collection, Cycles of Contingency: Developmental Systems and Evolution (Oyama, Griffiths, \& Gray, 2001). The three approaches have in common a focus on active organisms embedded in, choosing, and altering their environments. But DST is known to be rather infophobic, so again, we have a confluence of interests paired with diverse theoretical allegiances. Salient differences extend to attitudes toward the tropes of information storage, manipulation, and transmission. With an eye to the possibility of eventual integration, I would ask, What arguments can be mustered in favor of describing evolution by flows of hereditary information (rather than, say, reconstructed or stably present aspects of developmental systems)? What does infotalk enable and encourage; what does it prevent or deter? Once we accept the notion of information flow, how many conduits will be needed? Niche construction's three (genetic, ecological, cultural)? Jablonka and Lamb's (2005) four (genetic, epigenetic, behavioral, and cultural-symbolic)? Or perhaps an indefinite number, presumably rising, as Sterelny, Smith, and Dickison (1996) add to their catalog of extended replicators? A developmental system's dynamics are made up of short- and longer-term associations among its diverse constituents. Some linkages can be traced across the generations. Is it by invoking flows of immaterial information that we are most likely to gain understanding of the mechanisms by which these correlations are made, maintained, lost, or reconstructed? Or should we investigate the interactions themselves?

\section{Boundaries of Developmental Systems}

Opinions can differ within as well as among traditions. This brings us to our last boundary issues, concerning a pair of decisions made by my fellow DSTers Paul Griffiths and Russell Gray. DST aims to account for development and evolution in terms of organisms' intimate relations with their surrounds. In 1994 Griffiths and Gray abstracted from the variability of individual ontogenies, defining the "evolutionary developmental system" in terms of reliable reconstruction of the species-common life history. They thus employed multigenerational evolutionary criteria to define what is, nominally at least, a developmental complex. This idealized regularity stands in stark contrast with the multifarious variation of

\footnotetext{
${ }^{4}$ This last, of course, is the nature-nurture dichotomy read from development into evolution and then back again.
} 
what they then dubbed "individual developmental systems." My own writings contain only the latter, which supply both species-common regularities and the differences needed for evolutionary change; hence my hedged pronouns.

An organism's developmental system encompasses all contributors to its ontogeny: many interdependent interactants or resources, including not only the organism itself but factors beyond its skin, including other organisms and both variable and stable aspects of the larger environment. DST is sometimes said to show that the organism is a developmental system (e.g., Weber \& Depew, 2001), but the point is that the boundaries of the system are much more inclusive than those of the organism. Entities and influences are found at scales from the sub- to the supra-organismic, and the system includes the focal entity and its developmentally relevant surround, whether that entity is a cell, a cellular constituent, an organism, or a group of them.

DST's expanded account of developmental causation enlarges our view of heredity and evolution (Lickliter \& Berry, 1990, Oyama, 2000a,b; Oyama, Griffiths, \& Gray, 2001). For me, evolution is change in the constitution and distribution of developmental systems; transgenerational population processes are integral to the definition. The organism inherits an entire developmental system, but never passes on an identical one. Rather than limiting inheritance to the species-typical, as Griffiths and Gray $(1994,2001)$ do, I consider it to be what an organism gets, which is different both from what other organisms get and from what it gives or passes on to its offspring. The "view of heredity" several sentences back is not enlarged to the same degree for all of us.

Despite their disavowals, Griffiths and Gray's distinction between the variation of individual development and generalized, reliably reconstructed evolutionary life cycles threatens to reconstitute some of the very dualities they've helped to dismantle (e.g., Griffiths \& Gray, 1997, 2001, 2005). It seems, in fact, uncomfortably close to the traditional opposition between stably inherited species types and the vagaries of individual lifetimes. ${ }^{5}$ As they acknowledge, their focus on evolutionary constancy makes change seem a bit of a puzzle.

This leads to another boundary beef I have with Griffiths and Gray which has to do with their (2001) introduction of an additional environment around their evolutionary developmental system, which—recall—includes only relations with the reliably recurring (or persisting) developmental environment. They invoke this larger universal physical environment to account for selection pressure from

\footnotetext{
${ }^{5}$ Their definition of evolution (2001, p. 207) as "change in the nature of populations of developmental systems" suggests, perhaps inadvertently, a phylogenetic counterpart to the naturenurture pair. This suggestion grows stronger when they identify the regularity of the evolutionary developmental system with normality, contrasting it with deformity and individual difference. The internality of development is reinforced when they continue, "[T]his change is driven both endogenously, by the modification by each generation of developmental systems of the resources inherited by future generations, and exogenously, by modifications of these resources by factors outside the developmental system."
} 
environmental factors independent of the population in question. But the environment can only "exert selective pressure" by impinging on a population: that is, as Griffiths and Gray admit, by becoming part of (individual?) developmental systems. And an environmental factor can only be an interactant by virtue of the population of organisms in question, so in that sense its effects, in true DST fashion, are contingent on the rest of the system. It is worth noting that, following Lewontin (1982, 1983), DST has always rejected the image of a population adapting to problems set by an independent environment. Griffiths and Gray deny resurrecting that image. But then, I would ask, why invoke a broader independent environment when the evolutionary action occurs between a population and the environment relevant to it? It appears that they have reconstituted the internal-external polarity of traditional accounts of evolution (see note 5). Then, having abstracted away from the individual variation so crucial to evolutionary processes, they had get it back in. Their next moves were thus forced ones: a switch back to individual developmental systems to recapture the variation lost in their idealization as well as recourse to a wider, independent environment for (some) variation and change (2001, p. 208). They say we must switch back to individual developmental systems in order "to think about evolution," but that return calls into question the reason for abstracting from variation in the first place, for that move put "the causes of idiosyncratic development ... 'outside' the description ... of the typical developmental system of the lineage" (2001, p. 207). I remain puzzled by these decisions, and fear they leave Griffiths and Gray with something close to the orthodox framework they've resisted, a framework in which development is internal to the population, while natural selection is an external force or pressure.

There is much more to be said about these issues, and about related ones. For the moment I offer a caution: Until now we have all, principals and commentators alike, been rather too cavalier with $D S T$ and pronouns like they, their, us, we, our. At times quite substantive disagreements have been relegated to footnotes or ignored. In the end, however, it serves no one to go on letting such things slide. References to DST are fine for statements about a general approach to biological questions (its critique of the nature-nurture dichotomy, its notion of development as interactive construction, or its use of parity of reasoning, for instance), but specific construals of heredity and evolution, and indeed definitions of developmental systems themselves, are perhaps better attributed to specific theorists.

\section{CONCLUSION}

This quick tour of boundary issues has been at once an examination of the outlines of developmental systems and of DST's relations with its friends and neighbors-and even with itself. Although clarity and consistency are important 
virtues, I am genuinely uncertain whether concord, resolution, and integration are necessarily to be sought. When, if ever, should we be content with simply being next-door neighbors, tending our diverse gardens with our idiosyncratic tools, occasionally nodding warily at each other across the fence while a hundred flowers bloom?

\section{ACKNOWLEDGMENTS}

Exchanges with Lauren McCall, Dave McCandlish, Dan McShea, Gregory Mengel, Thomas Pradeu, Kriti Sharma, and Carl Simpson during the revision of this article were provocative, challenging, and very much appreciated.

\section{REFERENCES}

Avital, E., \& Jablonka, E. (2000). Animal traditions: Behavioral inheritance in evolution. Cambridge, UK: Cambridge University Press.

Bechtel, W. (2007). Biological mechanisms: Organized to maintain autonomy. In F. C. Boogerd, F. J. Bruggeman, J.-H. S. Hofmeyr, \& H. V. Westerhoff (Eds.), Systems biology: Philosophical foundations (pp. 269-302). Amsterdam: Elsevier.

Chemero, A., \& Turvey, M. T. (2008). Autonomy and hypersets. BioSystems, 91, 320-330.

Goodwin, B. C. (1970). Biological stability. In C. H. Waddington (Ed.), Towards a theoretical biology (Vol. 3, pp. 1-17). Chicago: Aldine.

Goodwin, B. C. (1982). Biology without Darwinian spectacles. Biologist, 29, 108-112.

Goodwin, B. C. (1984). A relational or field theory of reproduction and its evolutionary implications. In M.-W. Ho \& P. T. Saunders (Eds.), Beyond neo-Darwinism (pp. 219-241). London: Academic.

Goodwin, B. (1994). How the leopard changed its spots: The evolution of complexity. New York: Scribner's.

Griffiths, P. E., \& Gray, R. D. (1994). Developmental systems and evolutionary explanation. Journal of Philosophy, 91, 277-304.

Griffiths, P. E., \& Gray, R. D. (1997). Replicator II: Judgement day. Biology and Philosophy, 12, 471-492.

Griffiths, P. E., \& Gray, R. D. (2001). Darwinism and developmental systems. In S. Oyama, P. E. Griffiths, \& R. D. Gray (Eds.), Cycles of contingency: Developmental systems and evolution (pp. 195-218). Cambridge, MA: MIT Press/Bradford Books.

Griffiths, P. E., \& Gray, R. D. (2005). Discussion: Three ways to misunderstand developmental systems theory. Biology and Philosophy, 20, 417-425.

Jablonka, E. (2001). The systems of inheritance. In S. Oyama, P. E. Griffiths, \& R. D. Gray (Eds.), Cycles of contingency: Developmental systems and evolution (pp. 99-116). Cambridge, MA: MIT Press/Bradford Books.

Jablonka, E., \& Lamb, M. J. (1995). Epigenetic inheritance and evolution: The Lamarckian dimension. Oxford, UK: Oxford University Press.

Jablonka, E., \& Lamb, M. J. (2005). Evolution in four dimensions. Cambridge, MA: MIT Press.

Kauffman, S. A. (1983). Developmental constraints: Internal factors in evolution. In B. C. Goodwin, N. Holder, \& C. G. Wylie (Eds.), Development and evolution (pp. 195-226). Cambridge, UK: Cambridge University Press. 
Kauffman, S. A. (1985). Self organization, selective adaptation, and its limits: A new pattern of inference in evolution and development. In D. J. Depew \& B. H. Weber, (Eds.), Evolutionary theory at the crossroads: The new biology and the new philosophy of science (pp. 169-207). Cambridge, MA: MIT Press/Bradford Books.

Kauffman, S. A. (1993). The origins of order. Oxford, UK: Oxford University Press.

Laland, F., Odling-Smee, J., \& Feldman, M. F. (2001). Niche-construction, ecological inheritance and cycles of contingency in evolution. In S. Oyama, P. E. Griffiths, \& R. D. Gray (Eds.), Cycles of contingency: Developmental systems and evolution (pp. 117-126). Cambridge, MA: MIT Press/Bradford Books.

Lewontin, R. C. (1982). Organism and environment. In H. C. Plotkin (Ed.), Learning, development, and culture (pp. 151-170). New York: Wiley.

Lewontin, R. (1983). Gene, organism and environment. In D. S. Bendall (Ed.), Evolution from molecules to men (pp. 273-285). Cambridge, UK: Cambridge University Press.

Lickliter, R., \& Berry, T. (1990). The phylogeny fallacy. Developmental Review, 10, 348-364.

Maturana, H. R., \& Varela, F. J. (1987). The tree of knowledge. Boston: Shambhala/New Science Library.

Oyama, S. (2000a). Evolution's eye: A systems view of the biology-culture divide. Durham, NC: Duke University Press.

Oyama, S. (2000b). The ontogeny of information: Developmental systems and evolution (2nd ed., revised and expanded). Durham, NC: Duke University Press.

Oyama, S., Griffiths, P. E., \& Gray, R. D. (Eds.). (2001). Cycles of contingency: Developmental systems and evolution. Cambridge, MA: MIT Press/Bradford Books.

Poirier, P., Faucher, L., \& Lachapelle, J. (2005). The concept of innateness and the destiny of evolutionary psychology. Les Cahiers du LANCI, 4, 2005-01, 1-34.

Sterelny, K., Smith, K. C., \& Dickison, M. (1996). The extended replicator. Biology and Philosophy, $11,377-403$.

Thompson, E. (2007). Mind in life: Biology, phenomenology, and the sciences of mind. Cambridge, MA: Belknap/Harvard University Press.

Varela, F. J. (1979). Principles of biological autonomy. New York: Elsevier North Holland.

Weber, B. H., \& Depew, D. J. (2001). Developmental systems and the unity of science. In S. Oyama, P. E. Griffiths, \& R. D. Gray (Eds.), Cycles of contingency: Developmental systems and evolution (pp. 239-253). Cambridge, MA: MIT Press/Bradford Books. 